\title{
Efeitos genotóxicos e alterações de enzimas hepáticas em trabalhadores do refino de petróleo
}

\author{
Genotoxic effects and hepatic enzymes alterations among petroleum refinery workers
}

Rozana Oliveira Gonçalves'; Neli de Almeida Melo²; Fernando Martins Carvalho ${ }^{3}$; Roberto Charles Góes ${ }^{4}$

Unitermos
Exposição ocupacional
Refinarias de petróleo
Troca entre cromátides irmãs (TCI)
Alteraçōes cromossômicas (AC)
Gama-glutamil transferase (GGT)
Alanina aminotransferase (ALT)

Alanina aminotransferase (ALT)

\section{resumo}

Um estudo de casos e controles, aninhado num estudo de coorte, investigou a associação entre efeitos genotóxicos e alteração de enzimas hepáticas em trabalhadores de uma refinaria de petróleo do Nordeste. Foram examinados todos os dez novos casos de alterações de enzimas hepáticas - gamaglutamil transferase (GGT) e alanina aminotransferase (ALT) - ocorridos em 2002. Dez trabalhadores sem alterações de GGT ou ALT foram selecionados como controles. Os efeitos do fumo, sexo, idade e consumo de café foram controlados. O efeito genotóxico foi avaliado pela técnica de trocas entre cromátides irmãs (TCl) e alterações cromossômicas (AC) estruturais. As médias de TCl por célula $(3,92 \pm$ $1,04$ versus $4,25 \pm 1,47)$ e de $\operatorname{ACE}(8,85 \pm 3,4$ versus $9,1 \pm 3,7)$ não diferiram de forma significante entre casos e controles respectivamente. abstract

A case-control study, nested in a cohort study, investigated the association between genotoxic effects and hepatic enzymes alterations among workers in a petroleum refinery, Northeast Brazil. Ten cases of hepatic enzymes alterations - gamma-glutamyltransferase (GGT) and Alanine aminotransferase (ALT) - representing all incident cases occurring in the refinery during 2002, were examined. Ten workers without GGT and ALT alterations were selected as controls. The effects of smoking, sex, age and coffee consumption were controlled. The genotoxic effects were evaluated by the sister chromatid exchange (SCE) and by the chromosomal aberrations (CA) techniques. Mean SCE per cell $(3.92 \pm 1.04$ versus $4.25 \pm 1.47)$ and CA per cell $(8.85 \pm 3.4$ versus $9.1 \pm 3.7)$ did not differ significantly between cases and controls respectively.

\section{key words \\ Occupational exposure \\ Petroleum refinery \\ Sister chromatid exchanges \\ (SCE) \\ Chromosome aberrations (CA) \\ Gamma-glutamyltransferase \\ (GGT)}

Alanine aminotransferase (ALT)

\section{Introdução}

Petróleo e produtos petroquímicos são importantes poluentes ambientais, contendo uma complexa mistura de várias substâncias (benzeno, tolueno, óxido de etileno etc.) que podem causar lesões no material genético e potencialmente desencadear processos carcinogênicos em seres humanos ${ }^{(8)}$. Assim, trabalhadores de centros de distribuição de petróleo, expostos a níveis relativamente altos de vapores de combustíveis, apresentam maiores índices de trocas entre cromátides irmãs (TCl) e de alterações cromossômicas (AC) em linfócitos de sangue periférico do que trabalhadores não-expostos ${ }^{(4)}$.

A exposição prolongada a processos de tratamento de efluentes de uma grande indústria petroquímica foi

\footnotetext{
1. Especialista em Citogenética Humana; médica da Maternidade Climério de Oliveira da Universidade Federal da Bahia (UFBA).

2. Doutora em Ciências da Maternidade Climério de Oliveira da UFBA.

3. Doutor em Saúde Ocupacional do Departamento de Medicina Preventiva da UFBA.

4. Médico do Trabalho da Petróleo Brasileiro S/A (PETROBRAS).

Trabalho realizado no Laboratório de Citogenética Humana/Maternidade Climério de Oliveira, Departamento de Cinecologia e Obstetrícia, Departamento de Medicina Preventiva, UFBA. Financiamento: Financiadora de Estudos e Projetos (FINEP), Fundo Setorial do Petróleo e Gás Natural (CT-PETRO) e Conselho Nacional de Desenvolvimento Científico e Tecnológico (CNPq).
} 
associada a dano citogenético significativo, sendo mensurado pelas técnicas de $\mathrm{TCl}$ e de $\mathrm{AC}$ em linfócitos de sangue periférico ${ }^{(11)}$. Entretanto, outros estudos não revelaram aumento na freqüência de $\mathrm{TCl}$ e AC em trabalhadores expostos cronicamente a produtos petroquímicos ${ }^{(8,7)}$.

Recentemente, um conjunto de estudos revelou uma epidemia de alterações enzimáticas em trabalhadores de uma refinaria de petróleo na Bahia ${ }^{(10)}$. No parque petroquímico do Recôncavo Baiano, a ocorrência de casos de esteato-hepatite não-alcoólica (NASH) foi associada à exposição ocupacional crônica a produtos petroquímicos ${ }^{(5)}$. NASH é uma doença hepática com características histológicas semelhantes às encontradas na hepatite alcoólica, porém observada em indivíduos sem história de etilismo crônico. A doença é benigna, potencialmente reversível, mas também pode evoluir para cirrose ${ }^{(6)}$.

O objetivo deste trabalho foi investigar a associação entre efeitos genotóxicos ( $\mathrm{TCl}$ e $\mathrm{AC}$ ) e alteração de enzimas hepáticas (gama-glutamil transferase [GGT] e alanina aminotransferase [ALT]) em trabalhadores de uma refinaria de petróleo.

\section{Material e métodos}

Foi realizado um estudo de casos e controles com todos os 604 trabalhadores ativos de uma refinaria de petróleo do Nordeste, acompanhados durante o ano de 2002. Ocorreram, nesse período, 22 novos casos de elevação simultânea de GGT e ALT. Foram excluídos do estudo os fumantes e aqueles fora da faixa etária entre 30 e 40 anos, restando assim 10 casos, bem como foram selecionados, aleatoriamente, dez controles. Cada caso foi pareado com seu respectivo controle sem qualquer alteração enzimática, com idade aproximada de \pm 5 anos e consumo de café semelhante. Todos os casos e controles eram do sexo masculino.

Em junho/julho de 2003, uma amostra de $5 \mathrm{ml}$ de sangue periférico foi tomada de cada trabalhador para as análises citogenéticas. Para cada indivíduo foram realizadas duas culturas para $\mathrm{AC}$ e duas para $\mathrm{TCl}$, cultivadas a $37^{\circ} \mathrm{C}$ por 48 e 72 horas, respectivamente, usando $1 \mathrm{ml}$ de sangue total em $9 \mathrm{ml}$ de meio de cultura (RPMI 1640) suplementado com $20 \%$ de soro bovino fetal, $2 \%$ de estreptomicina, $2 \%$ de fitoemaglutinina (PHA) e $10 \mu \mathrm{g} / \mathrm{ml}$ de bromodesoxiuridina $(\mathrm{BrDu})$ da Sigma (para TCl), perfazendo um total de $10 \mathrm{ml}$. Para o estudo de $\mathrm{TCl}$, as lâminas foram tratadas com solução de Hoechst (Sigma) a 10\% sob luz ultravioleta por 45 minutos, aquecidas em solução de fosfato de sódio dibásico
(Na2HPO4) a 1 molar, e $\mathrm{pH}=8$, entre $87^{\circ}$ e $98^{\circ} \mathrm{C}$, por 10 a 30 segundos, e coradas com Giemsa.

Foram analisadas 30 metáfases em teste cego por indivíduo para $\mathrm{TCl}, 30$ para $\mathrm{AC}$ e 400 células para o cálculo do índice mitótico. Para comparação de médias dos grupos caso e controle, utilizou-se o teste t para amostras pareadas $^{(9)}$.

\section{Resultados}

As médias de TCl foram $3,92 \pm 1,04$ e 4,25 $\pm 1,47$ $(p=0,78)$ para casos e controles, respectivamente. As médias de AC estruturais foram $8,85 \pm 3,4$ e 9,1 $\pm 3,7(p=0,864)$ para casos e controles, respectivamente. Exceto um indivíduo do grupo caso, todos os 19 trabalhadores estudados apresentaram freqüência de AC acima de $4 \%$ (Tabela).

O índice mitótico observado em casos e controles foi de 1,92 $\pm 1,24$ e $2,75 \pm 1,35$ ( $p=0,23)$, respectivamente, não evidenciando diferenças estatisticamente significativas entre os dois grupos. Um cromossomo dicêntrico foi encontrado em um dos controles e uma figura quadrirradial, em um dos casos.

Este trabalho não mostrou associação significativa entre alterações de enzimas hepáticas e efeitos genotóxicos, mensurados pelas técnicas de $\mathrm{TCl}$ e de AC. As freqüências médias de $\mathrm{TCl} /$ células examinadas em casos e em controles $(3,92 \pm 1,04$ e 4,25 $\pm 1,47$, respectivamente) estão abaixo daquelas encontradas em amostras da população geral: $6,95-14,65^{(2)}$ e $8,88-10,48^{(1)}$.

Chamou atenção a elevada proporção de trabalhadores (casos e controles) com freqüência de alterações cromossômicas estruturais acima de $4 \%$, que é o valor esperado para populações normais ${ }^{(3)}$. Inicialmente, deve-se ponderar se esses resultados podem estar refletindo o uso de diferentes metodologias laboratoriais citogenéticas. Também pode ser aventado que o tamanho da amostra estudada foi muito pequeno, apesar de reunir todos os casos novos ocorridos na refinaria durante um ano.

Finalmente, pode-se cogitar o fato de que os resultados elevados de $\mathrm{AC}$ e baixos de $\mathrm{TCl}$, para os 20 trabalhadores estudados, podem estar refletindo a verdadeira freqüência de AC e TCI na população total da refinaria. Nesta hipótese, a exposição ocupacional a compostos petroquímicos seria a responsável pelos resultados encontrados. É recomendada a realização de estudo para comparar a prevalência de $A C$ e $\mathrm{TCl}$ dos trabalhadores dessa refinaria com os de uma população externa, de referência. 


\begin{tabular}{|c|c|c|c|c|}
\hline & \multicolumn{4}{|c|}{$\begin{array}{l}\text { Médias de trocas entre cromátides irmãs (ICI) e alterações cromossômicas estruturais (AC) } \\
\text { em trabalhadores do refino de petróleo com (caso) e sem (controle) alteraçöes de enzimas } \\
\text { hepáticas (Mataripe, 2003) }\end{array}$} \\
\hline \multirow[b]{2}{*}{ Trabalhador } & \multicolumn{2}{|c|}{ TCI } & \multicolumn{2}{|c|}{$\mathrm{AC}$} \\
\hline & Caso & Controle & Caso & Controle \\
\hline 1 & 5,4 & 2,9 & 6,46 & 6,96 \\
\hline 2 & 4,23 & 3,43 & 11,73 & 5,38 \\
\hline 3 & 4,73 & 3,46 & 7,5 & 10,12 \\
\hline 4 & 3 & 5,4 & 7,32 & 6,75 \\
\hline 5 & 3,9 & 6,3 & 15,6 & 8,46 \\
\hline 6 & 3,16 & 3,5 & 11,12 & 16,15 \\
\hline 7 & 3,46 & 7,13 & 11,89 & 6,53 \\
\hline 8 & 2,56 & 3 & 8,23 & 6,2 \\
\hline 9 & 4,5 & 3,83 & 6,98 & 15,92 \\
\hline 10 & 4,3 & 3,73 & 2,13 & 8,93 \\
\hline $\begin{array}{l}\text { Média } \pm \text { desvio } \\
\text { padrão }\end{array}$ & $3,92 \pm 1,04^{*}$ & $4,25 \pm 1,47^{*}$ & $8,85 \pm 3,4^{* *}$ & $9,10 \pm 3,7^{\text {* * }}$ \\
\hline
\end{tabular}

\section{Referências}

1. ALMEIDA-MELO, N. Estudo da ação do ultra-som pulsado em cultura temporária de linfócitos humanos. São Paulo, 1984. Tese (Doutoramento), Instituto de Biociências, Universidade de São Paulo, São Paulo.

2. CROSSEN, P. E. SCE in lymphocytes. In: SANDBERG A. A. (ed.) Progress and topics in cytogenetics, New York:Alan R. Liss, Inc.; 1982. chapter I I, p. 175-93, v. 2.

3. BEIGUELMAN, B. Citogenética humana. I ed. Rio de Janeiro: Guanabara Koogan, 1982.

4. CARERE, A. et al. Genetic effects of petroleum fuels: cytogenetic monitoring of gasoline station attendants. Mutat Res, v. 332, p. 17-26, 1995.

5. COTRIM, H. P. et al. Nonalcoholic steatohepatitis: a toxic liver disease in industrial workers. Liver, v. 19, p. 299-304, 1999.

6. COTRIM, H. P. et al. Clinical and histopathological features of $\mathrm{NASH}$ in workers exposed to chemicals with or without associated metabolic conditions. Liver Int, v. 24, p. I31-5, 2004.

7. FREDGA, K.; REITALU, J.; BERLINE, M. Chromosome studies in workers exposed to benzene: genetic damage in man caused by environmental agents. New York: Academic Press; 1979. p. 187-203.

8. KHALIL,A. M.; QASSEM,W:; KAMAL, O. M. No significant increase in sister-chromatid exchanges in cultured blood lymphocytes from workers in a large oil refinery. Mutat Res, v. 312, p. |87-9|, 1994.

9. SPSS for Windows. Release 6.I. Chicago: SPSS Inc.; 1994.

I0. MENDES, J. L. B.; CARVALHO, F. M.; SILVANY-NETO, A. M. et al. Alterações hepáticas em trabalhadores de uma refinaria de petróleo e em uma população de referência no Estado da Bahia, Brasil. Rev Panam Salud Pública, 2004 (no prelo).

I I. ZHOU, X. et al. Cytogenetic monitoring of petrochemical workers. Mutat Res, v. 175, p. 237-42, 1986.

\begin{tabular}{l|l} 
& Endereço para correspondência \\
\hline & Rozana Oliveira Conçalves \\
& Rua Comendador Horário Urpia Ir., 161/apto. \\
& 302 - Ed. Monroe Graça \\
CEP 40.150-250 - Salvador-BA & \\
Tel:: (71) 3235-5306 \\
e-mail: rozana.oliveira@bol.com.br
\end{tabular}

